WZB

\title{
Uma Revisão Cienciométrica da Governança e dos Conflitos em Empresas Familiares
}

\author{
A Scientometric Review of Governance and Conflicts in Family Businesses
}

Moacir Porto Ferreira

Mestre em Sistemas de Gestão pela Universidade Federal Fluminense Doutorando em Administração pela Universidade do Grande Rio E-mail: moacir.ferreira@unigranrio.br

Josir Simeone Gomes Pós-Doutorado em Administração. Universidad Carlos III de Madrid, UCIIIM, Espanha. Doutor em Administração pela Universidade Federal do Rio de Janeiro Professor do Programa de Doutorado da Universidade do Grande Rio E-mail: josir.gomes@unigranrio.edu.br

Flávio Bretanha Freire Mestre em Engenharia de Transporte pela UFRJ Sócio Diretor da Luth Consultoria E-mail: flaviobretanha@luth.com.br

Endereço: Moacir Porto Ferreira

Rua Professor José de Souza Herdy, 1160 - Jardim Vinte e Cinco de Agosto, Duque de Caxias - RJ, 25071-202, Brasil.

Endereço: Josir Simeone Gomes

Rua Professor José de Souza Herdy, 1160 - Jardim Vinte e Cinco de Agosto, Duque de Caxias - RJ, 25071-202, Brasil.

Endereço: Flávio Bretanha Freire

Av Franklin Roosevelt 39/sala 1120, Rio de Janeiro. CEP: 20021-120, Brasil.
Editor-Chefe: Dr. Tonny Kerley de Alencar Rodrigues

Artigo recebido em 26/08/2021. Última versão recebida em 09/09/2021. Aprovado em 10/09/2021.

Avaliado pelo sistema Triple Review: a) Desk Review pelo Editor-Chefe; e b) Double Blind Review (avaliação cega por dois avaliadores da área).

Revisão: Gramatical, Normativa e de Formatação 


\title{
RESUMO
}

O objetivo deste trabalho é fornecer uma compreensão do status quo e da tendência das pesquisas sobre conflito de interesses em empresas familiares, identificando as diferentes formas de materialização desse tipo de conflito, além de propor algumas medidas de mitigação para reduzir os impactos de imagem, de reputação, do financeiro e legal regulatório nas firmas. Esta pesquisa utiliza a revisão cienciométrica da pesquisa de conflito de interesses e governança corporativa e empresas familiares entre 1998 e 2019, por meio de análise de palavras, análise de coautor, análise de periódico, análise de instituição e análise de país. Após refino, um total de 46 registros bibliográficos da base de dados da Scopus foi selecionado e analisado. Introduzimos discutindo os problemas da agência que a governança corporativa enfrenta e como eles se manifestam nas empresas familiares, como conflitos de interesse, a saber: (a) acionistas e administradores (Agency Problem I), (b) acionistas controladores familiares e acionistas não controladores minoritários (Agency Problem II), (c) acionistas e credores (Agency Problem III), e (d) acionistas da família e membros da família em geral que não acionistas, nem administradores e nem membros do conselho (Agency Problem IV). Posteriormente, analisamos o conflito principal-principal, existente entre acionistas familiares e outros acionistas. Os resultados revelam uma lacuna do campo de pesquisa de práticas de governança voltadas para tratamento de conflitos de interesses em empresas familiares com foco nos colaboradores e prestadores de serviços que não sejam membros da família, acionistas, membros do conselho e nem gestores.

Palavras-chave: Conflitos de Interesse. Empresas Familiares. Governança Corporativa.

\begin{abstract}
The objective of this work is to provide an understanding of the status quo and the trend of research on conflicts of interest in such companies, identifying the different forms of materialization of this type of conflict, in addition to proposing some mitigation measures to reduce the impacts of image, of reputation, financial and legal regulatory framework in firms. This research uses the scientometric review of the conflict of interest and corporate governance and family businesses research between 1998 and 2019, through word analysis, co-author analysis, journal analysis, institution analysis and country analysis. After refining, a total of 46 bibliographic records from the Scopus database were selected and analyzed. We introduce by discussing the agency problems that corporate governance faces and how they manifest themselves in family businesses, as conflicts of interest, namely: (a) shareholders and managers (Agency Problem I), (b) family controlling shareholders and non-controlling shareholders minority shareholders (Agency Problem II), (c) shareholders and creditors (Agency Problem III), and (d) family shareholders and family members in general other than shareholders, directors or board members (Agency Problem IV). Afterwards, we analyze the main-main conflict, existing between family shareholders and other shareholders. The results reveal a gap in the field of research on governance practices aimed at dealing with conflicts of interest in family businesses with a focus on employees and service providers who are not family members, shareholders, board members or managers.
\end{abstract}

Keywords: Conflicts of Interest. Family Businesses. Corporate Governance. Management Control System. 


\section{INTRODUÇÃO}

Ao pesquisarmos artigos com as palavras-chaves "conflitos de interesse", "empresas familiares" e "governança corporativa", verificou-se a existência de uma lacuna de estudos conciliando todos esses termos e palavras-chaves. Mesmo nos Estados Unidos, onde a propriedade é relativamente dispersa, segundo La Porta et al. (1999) e Anderson e Reeb (2003), as famílias estão presentes em um terço do S\&P 500 e respondem por $18 \%$ do patrimônio líquido em circulação. Além disso, pesquisas recentes documentam que as empresas familiares apresentam diferenças significativas em relação às empresas não familiares em muitas dimensões contábeis, incluindo assimetria de informações, qualidade dos ganhos, governança corporativa, valor da empresa e desempenho (CHAU; GRAY, 2010).

Em resumo, é evidente a importância dessas empresas na sociedade em todo o mundo. Empresas familiares "mostram determinadas características diferentes das demais organizações, como os valores, os laços de seus membros, o processo sucessório, a relação entre família e empresa e a figura do fundador, que formam a identidade das empresas familiares" (TROCCOLI; LISBOA, 2018).

As peculiaridades das empresas familiares são evidentes e "é por causa dessas particularidades que é preciso uma forma diferente de analisar essas empresas, tanto perante o processo sucessório, quanto aos outros diferenciais oferecidos por um fundador que precisa pensar na passagem da direção do seu negócio" (TROCCOLI; LISBOA, 2018).

Nas empresas familiares "é comum que os membros da família participem da gestão de forma profissional, mas também é comum a gestão ser feita por pessoas sem preparo profissional para a função ou que simplesmente estão lá apenas a título de remuneração e pouco contribuem para o sucesso do negócio" (CURADO apud PAN et al., 2019). Ainda sobre profissionalismo nesse perfil de empresa, gerentes e diretores frequentemente misturam sentimentos e características pessoais. Nesse sentido,

(...) em busca de soluções às suas necessidades individuais, os membros da família podem colocar o emocional de tal forma que transpõe o nível racional das coisas e colocam em risco a organização, obrigando a tomada de decisões que podem, ao invés de solucionar, gerar maiores conflitos e por fim rupturas. (MAMEDE ET Al., 2019).

Empresas familiares têm níveis mais elevados de conflito cognitivo. Esse se materializa tanto no serviço quanto nas tarefas de controle. Além disso, a demonstrada correlação negativa entre conflito cognitivo e uso do conhecimento e habilidades sufoca o 
compartilhamento de informações e aprendizagem coletiva (ZONA, 2014). O conflito cognitivo desencadeia conflito de relacionamento e desconforto pessoal (JEHN, 1995), o que ratifica a visão de Zona (2014), pois há tendência reduzida de cooperar e utilizar comitês técnicos ou temáticos nesses ambientes. Dessa forma, destaca-se o iminente e frequente conflito de interesse.

Os conflitos de interesses expõem muitas vezes as famílias perante a sociedade. Por isso a importância de haver uma evolução na maneira de pensar da família empresária. Quanto maior o nível de capacitação das famílias empresárias, maior será a contribuição para o desenvolvimento dos negócios. (RICCA, 2007).

Portanto, a presença de dois conselheiros externos à empresa, recrutados e escolhidos por terceiro é fundamental para que o conselho de administração seja o mais isento possível.

O momento econômico de COVID-19 exige mais profissionalismo, dedicação e persistência. Adicionalmente, a concorrência é internacional, em rede, e com as exigências de aprimoramento em que vivem as empresas familiares, é crucial pensar o processo decisório da empresa. Ter clareza da relação da família com a instituição, os interesses da propriedade e os da empresa é o princípio da longevidade empresarial (MAMEDE et al., 2019).

Adicionalmente, após anos, a rotina do CEO pode ser induzida na reanálise ou verificação da estratégia da empresa. As famílias empresárias, mesmo sendo elas proprietárias de poucos bens, possuem responsabilidades que vão além do âmbito familiar e passam a ter responsabilidade social. Banalizar a administração e a sucessão da empresa familiar compromete não só seu funcionamento, mas a vida de terceiros que dela dependem. Neste artigo pretende-se estudar aspectos quantitativos da ciência e da produção científica, considerando confllitos e governança corporativa em empresas familiares, entre 1998 e 2020.

O Conselho Administrativo(C.A) supervisiona atividades gerenciais da empresa e norteia a estratégia. É ele que dá as orientações gerais dos negócios, bem como seu parecer sobre as contas. O objetivo principal do Conselho é maximizar o retorno dos investimentos. Para isso, compete a ele o desenvolvimento de questões estratégicas, como na busca de novos negócios e na criação de vantagens competitivas duradouras. Esse estudo apresenta o Conselho como principal ferramenta de governança corporativa para mitigar conflitos em empresas familiares.

Os problemas e soluções discutidos no CA dizem respeito ao mundo real, complexo e relacionado à geração de valor no longo prazo. Nesse sentido, a adoção de conselheiros externos competentes e isentos pode se mostrar ferramenta de mitigação de conflitos e 
obtenção de melhores resultados. A natureza dos problemas reais pode ser complexa e "a relação crescentemente complexa entre essas realidades, as novas tecnologias permitindo o compartilhamento de dados e informações, tudo leva à abordagem interdisciplinar, na qual o resultado é superior à soma das partes" (PHILIPPI JR., 2017). Adicionalmente, ante a complexidade e a dimensão dos problemas globais contemporâneos e os desafios científicotecnológicos aí colocados, fica evidente que seu enfrentamento requer esforços conjuntos e colaborativos, de abrangência interdisciplinar e internacional (MACIEL; ALBAGLI, 2010).

\section{REFERENCIAL TEÓRICO}

Os conflitos de interesses aparecem como consequência de desejos divergentes entre os acionistas e a alta administração (problemas principal-agente) e entre os acionistas (problemas principal-principal), embora também outras relações com as partes interessadas sejam afetadas e coordenadas por meio da governança corporativa.

\subsection{Conflito de Interesses}

De acordo com a lei 12.803/13, conflito de interesses é a situação gerada pelo confronto entre interesses públicos e privados, que possa comprometer o interesse coletivo ou influenciar, de maneira imprópria, o desempenho da função pública. Já a ISO 37001 define o conflito de interesse como "uma situação em que interesses comerciais, financeiros, familiares, políticos ou pessoais possam interferir no julgamento de pessoas no desempenho de suas funções para com a organização”. A Lei 13.303/2016, por outro lado, trata situações de conflito de interesses no âmbito das contratações realizadas pelas empresas. O conflito de interesses é uma questão inerente às relações humanas estando presente nas mais diversas áreas, conforme figura 1: 
Figura 1 - conflitos de interesses nas mais diversas áreas

\begin{tabular}{l} 
Jurídica \\
\hline •Exemplos de \\
conflitos estão \\
relacionados à \\
relação \\
advogado/cliente, \\
na qual o \\
advogado pode \\
rompero dever \\
de sigilo com o \\
cliente. Em \\
relaçãoa \\
impedimento e \\
suspeição de juiz, \\
pode haver \\
relação de \\
amizade, \\
parentesco, ou \\
outro \\
envolvimento \\
afetivo do juiz \\
com uma das \\
partes, tornando- \\
o parcial na \\
decisão;
\end{tabular}
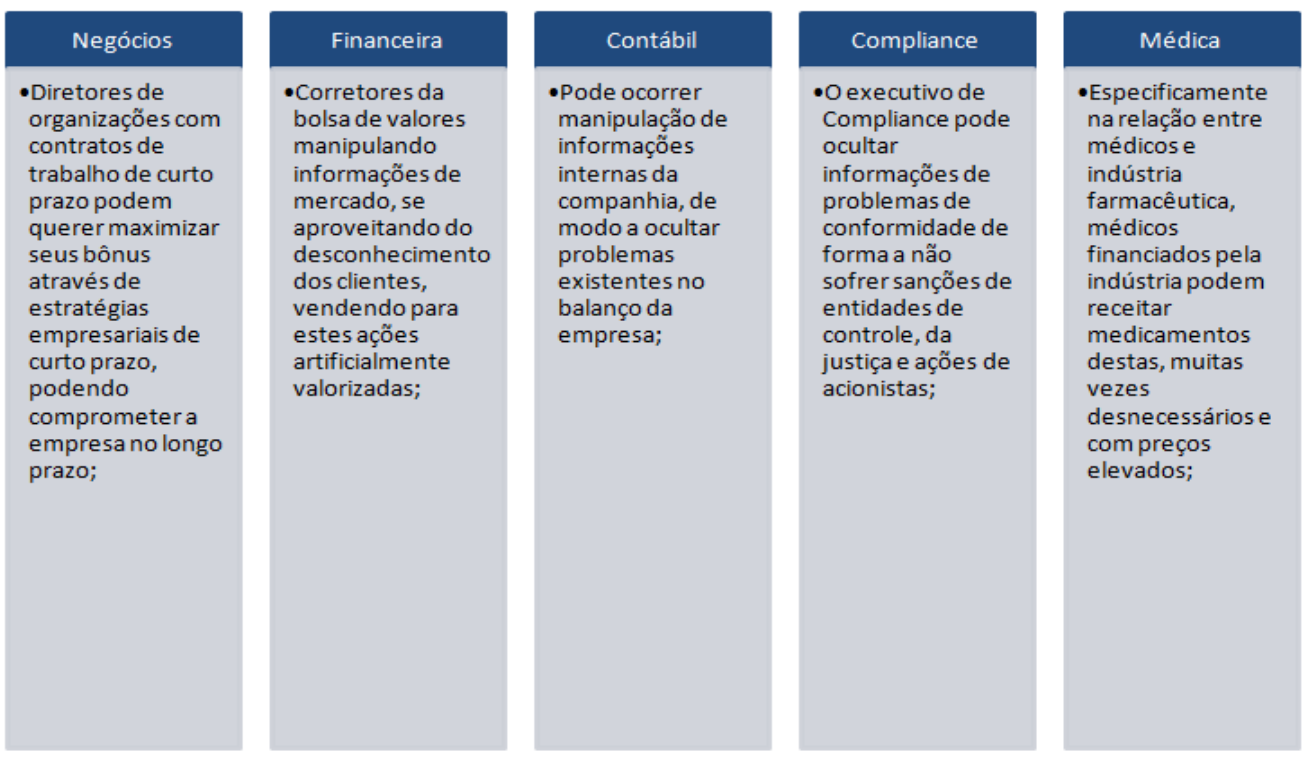

Fonte: Os autores do trabalho (2021).

Conflitos de interesses impõem riscos à corporação, além dos que lhe são de natural imputação. Elencar riscos e atuar na sua mitigação mostra-se uma oportunidade, uma vantagem competitiva às corporações. Colares de Oliveira e Linhares (2007) afirmam que o gerenciamento de riscos é necessário para prevenir possíveis erros, fraudes ou processos que possam gerar impactos negativos para a organização, cuja adequada identificação tanto minimiza perdas como pode oferecer à corporação vantagens competitivas.

Para o exercício de uma boa governança corporativa é necessária a implantação de técnicas para identificação, avaliação e controle de riscos. Para que o gerenciamento de riscos seja um sucesso, é preciso que os líderes das organizações possam enxergá-lo como uma forma de gerar valor aos acionistas (COLARES DE OLIVEIRA; LINHARES, 2007).

\subsection{Conflito principal-agente}

Em grandes empresas onde há separação de propriedade e administração, o problema principal-agente ou conflito de agência pode surgir entre a alta administração ("agente") e os acionistas ("principal "). Esses podem ter interesses diferentes, onde os acionistas normalmente desejam lucro, e a alta administração pode ser motivada por motivos como remuneração, boas condições de trabalho ou bons relacionamentos no local de trabalho, na medida em que estes não são necessários para lucros. 
O conflito principal-agente também se materializa na compra de ações. Os executivos podem ter incentivos para desviar o lucro da empresa para a compra de ações da própria empresa, o que fará com que o preço das ações suba. No entanto, os lucros retidos não serão usados para comprar equipamentos ou para contratar pessoal de qualidade. Como resultado, os executivos podem sacrificar os lucros de longo prazo em troca de benefícios pessoais de curto prazo. Pode ser difícil detectar, pois ver suas próprias ações subindo é gratificante.

Andre, Ben-Amar e Saadi (2012) sugerem que o potencial conflito de agência entre acionistas e a administração profissional tem um impacto prejudicial no retorno de investimento dos compradores, numa fusão ou aquisição, com risco de incrementar potencial conflito entre grandes e pequenos investidores. Esse conflito traz impacto negativo adicional na geração de riqueza. É possível que o mercado espere a presença de excesso de controle familiar para amplificar os custos de agência associados com o conflito entre acionistas e gestores profissionais (ANDRE; BEN-AMAR; SAADI, 2012).

\subsection{Conflito principal-principal}

O problema do principal-agente pode ser intensificado quando a alta administração age em nome de vários acionistas - o que costuma ser o caso em grandes empresas (problema de múltiplos principais). Nas empresas familiares a preocupação é que os administradores possam atuar para a família controladora, mas não para os acionistas em geral. Diversos estudos convergem que pelo menos parcialmente os custos de agência dependem da combinação de condições. Famílias controladoras podem usar o gerenciamento de resultados para ocultar a expropriação dos acionistas minoritários (ISHAK et al., 2011. STOCKMANS et al., 2013).

Em geral, os proprietários da família têm um fraco desempenho com carteiras diversificadas. Como resultado, eles geralmente seguem estratégias de negócios avessas ao risco. Assim, na visão de Azoury e Bouri (2015), os proprietários da família têm um grande interesse em ter controle sobre a tomada de decisão firme através da nomeação de membros da família em cargos- chave de gestão. As empresas familiares costumam empregar membros da família independentemente de conflitos. Isso lhes dá incentivos para priorizar seus próprios interesses e criar benefícios às custas dos acionistas minoritários. A nomeação de menos do que qualificados membros da família como CEOs pode encorajar adesão, esquiva e outras formas de comportamentos de autonegociação (SCHULZE et al. 2003). 
Goh, Rasli e Khan (2014) desenvolveram estudos em 141 empresas familiares de capital aberto, onde descartam a dualidade do CEO (exercendo os dois papéis) como moderador da relação entre controle e desempenho da empresa. Por um lado, espera-se que os proprietários das famílias possam fortalecer o controle por meio da dualidade do CEO e ignorar os demais interesses. Porém, por outro lado, isso pode enfraquecer o controle e monitoramento mais desejado pelos demais acionistas. Essa descoberta pode explicar por que os proprietários podem resistir e enfraquecer o controle por meio do CEO em empresas familiares.

Na teoria econômica, o termo "conflito de agência" se refere ao perigo de que os indivíduos ajam de forma a servir aos seus próprios objetivos e que esses objetivos entrem em conflito com os da organização, como uma corporação, e seus constituintes, como os acionistas.

\subsection{Mecanismos de Controle}

Adotar medidas que efetivamente assegurem e promovam equilíbrio entre os stakeholders das organizações é de fundamental importância. A compreensão dos mecanismos disponíveis na empresa para alinhar os objetivos propostos, proporcionando transparência e controle dos atos praticados pelos gestores, os mecanismos bem aplicados alinham a empresa às imposições do mercado (CONZATTI; BENSEN; JUNIOR, 2021).

As empresas com elevado grau de Integridade geralmente mitigam riscos de conflito de interesses através da implantação de um Programa de Integridade, com uma política específica para conflito de interesses, exemplificando os processos mais expostos, formas de materialização, medidas de mitigação e formas de tratamento e reporte das ocorrências identificadas. O programa orienta o caráter prejudicial aos negócios e ao ambiente de controles internos, pois pode influenciar de maneira imprópria a conduta dos empregados.

Com o surgimento da Governança Corporativa, vinculado ao problema de agência os mecanismos da governança permitem determinar controles para avaliar os administradores por suas decisões (CUNHA; RODRIGUES, 2018; CONZATTI et al, 2021). A essência, então, a ser desenvolvida e observada pela área de Compliance, passa a ser a mitigação de fatores de risco, com os quais as organizações operam constantemente com intensidade.

Em essência, essa mitigação recorre a ferramentas - aqui descritas como mecanismos que permitam a Gestão garantir a aderência aos controles internos e externos, coadunados 
com os objetivos empresariais. Tem-se, como mecanismos de gestão e controle dos fatores de risco: controle, políticas e procedimentos.

\subsubsection{Controle}

Alguns dos conflitos tendem a se apresentar em situações em que são baixas as iniciativas de rotineiras verificações ou checagens, por movimentos de controle insuficientes. Entre as possibilidades de conflito elencadas por ausência de controle, podem ser citadas:

a. Falta de verificação periódica da existência de empregados ou de seus parentes atuando como sócios-gestores ou como representantes de contrapartes relacionados à empresa;

b. Ausência de verificação prévia para garantir que representantes de contratadas não participem de processos de contratação/licitação na empresa;

c. Falta de verificação prévia da existência de relação de amizade ou parentesco entre fiscal/gerente de contrato e prestador de serviço.

\subsubsection{Políticas}

Tornar claras as regras corporativas que sejam aderentes aos dispositivos legais ou normatizados pelo Estado, fundamental às políticas corporativas que embasam o Compliance. Há de se verificar que tais políticas costumam ser mais rigorosas quando avaliadas no contexto local de atuação das firmas, em especial as transnacionalizadas. $\mathrm{O}$ desconhecimento do regramento local pode inferir a políticas de Compliance parcialmente equivocadas e ineficientes. A elaboração de tais políticas pode evitar alguns conflitos, entre eles:

a. Falta de uma Política de Indicação de membros do Conselho de Administração (CA), do Conselho Fiscal e da Diretoria Executiva, e demais membros correlatos, isto é, requisitos e impedimentos estabelecidos para os membros do CA;

b. Falta de uma Política de Transações com Partes Relacionadas que oriente Transações com Partes Relacionadas e em situações em que exista potencial conflito de interesses;

c. Falta de política de oferecimento e recebimento de brindes e presentes;

d. Falta de revisão da política de transações com partes relacionadas; 
e. Falta de Política Concorrencial, que reforce o compromisso da empresa com o cumprimento estrito da legislação de defesa da concorrência ou antitruste nacional e das jurisdições estrangeiras em que a empresa realiza negócios;

f. Falta de política para cargo de administração, que suprima conflitos de interesse com a empresa e observe, integralmente, os requisitos e vedações legais.

\subsubsection{Procedimentos}

A implementação de políticas requer que haja comunicação e orientação de condutas que previnam ou que informem as práticas com conflitos de interesse que adversem com o Compliance - o chamado no compliance. Assim, meios de como proceder diante das práticas no compliance se torna relevante tanto quanto a existência de políticas afins. Podem ser citados os conflitos que denotem ausência de procedimentos:

a. Falta de dispositivo para evitar que um acionista, tendo um conflito de interesses com a companhia, vote em decisões inerentes ao conflito;

b. Falta de dispositivo que garanta a sanção para os assuntos relacionados a conflito de interesses;

c. Falta de dispositivo de recusa de apoio para partidos políticos ou campanhas;

d. Falta de treinamento realizado de forma contínua, abordando questões éticas e sustentabilidade empresarial;

e. Falta de definição de procedimentos internos específicos de pré-aprovação dos serviços contratados junto aos seus auditores externos.

f. Falta de dispositivo que evite qualquer conflito de interesse ou impropriedade na negociação com valores mobiliários de emissão da empresa;

g. Falta de dispositivo que preveja hipóteses de conflito de interesses posterior ao término de gestão dos administradores e membros do conselho fiscal;

h. Falta canal ou comunicação disponíveis aos empregados para a realização de consultas sobre potenciais situações de conflito de interesses.

\section{METODOLOGIA}

Esta pesquisa utiliza a revisão cienciométrica da pesquisa de conflito de interesses e governança corporativa e empresas familiares entre 1998 e 2019, por meio de análise de co- 
palavras, análise de coautor, análise de periódico, análise de instituição e análise de país. Um total de 46 registros bibliográficos da base de dados da Scopus foi selecionado e analisado.

Os dados cienciométricos são apresentados por meio de informações combinadas na forma de tabelas, gráficos e figuras como redes e mapas de densidade, apresentando um mapa da pesquisa global em empresas familiares, conflitos e governança corporativa, e os principais atores desta área temática em 1998 e 2020. O gráfico 1 apresenta os dados sobre a evolução da publicação de artigos de pesquisa.

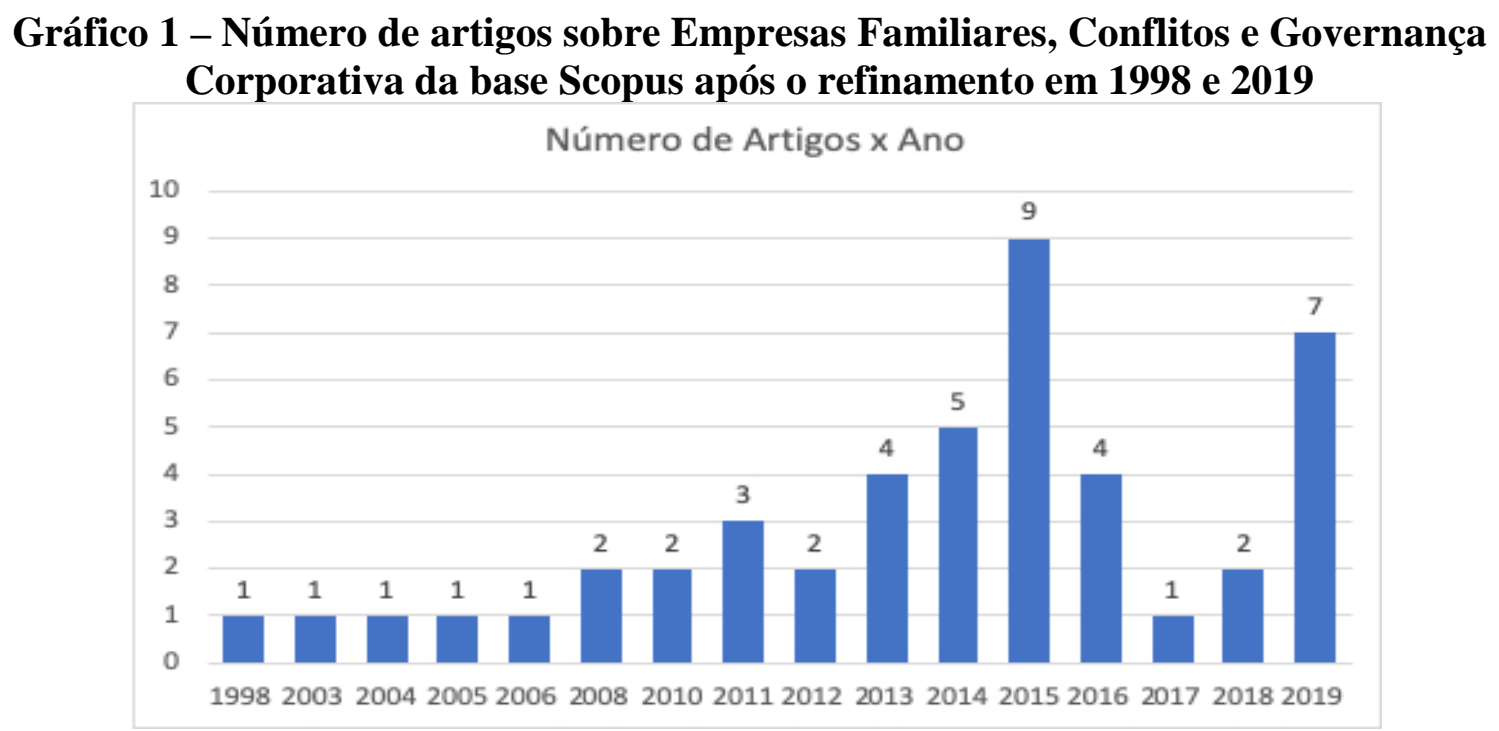

Fonte: Os autores do trabalho (2021).

\subsection{Projeto experimental, materiais e métodos}

\subsubsection{Aquisição dos Dados}

As buscas realizadas retornam pequeno número de publicações. Neste artigo seguimos uma metodologia proposta por Treinta et al. [1]. Após avaliar os conceitos básicos relacionados à empresa familiar, conflito e governança corporativa, os seguintes códigos de recuperação foram usados na coleção da Scopus (Tabela 1) e só foram buscados artigos em inglês.

No total, 46 artigos foram extraídos, exportados e carregados no software Mendeley®, onde seguimos etapas descritas na Figura 2 para refinar a coleta dessa base de dados. As Figuras: 4 - Rede de palavras-chave co-ocorrentes; 5 - Visualização da densidade do item de palavras-chave co-ocorrentes e 6 - Visualização da rede de co-autoria, e Tabela 3 - 6 palavraschave co-ocorrentes mais frequentes foram geradas usando o VOSviewer®. Ao final desse 
processo de refinamento, um total de 37 registros bibliográficos foi selecionado como a coleção final do banco de dados a ser considerada em nossa análise. O Microsoft Excel foi utilizado para consolidar dados e formatação das informações dos artigos por ano, autores mais produtivos, coautores e periódicos. Para apoiar nossa análise bibliométrica, também utilizamos o VOSviewer - uma ferramenta de software para construir e visualizar redes bibliométricas. Essas redes podem incluir, por exemplo, periódicos, pesquisadores ou publicações individuais, e podem ser construídas com base em relações de citação, combinação bibliográfica, co-citação ou coautoria. Com o VOSviewer exportamos frequência de palavras, para identificar as palavras mais frequentes, gerando assim uma "nuvem de palavras" e "Pesquisa de texto" para as mesmas palavras-chave utilizadas como códigos de recuperação para as bases de dados, salvando os dados como códigos para essas palavraschave.

Tabela 1 - Pesquisa executada na base Scopus

\begin{tabular}{|c|c|c|}
\hline Base de Dados & Palavras-chave & Documentos \\
\hline Scopus & $\begin{array}{c}\text { TITLE-ABS-KEY ("family firm" OR "family firms") AND } \\
\text { TITLE-ABS-KEY (conflict) AND TITLE-ABS-KEY } \\
\text { ("corporate governance") }\end{array}$ & 46 \\
\hline Scopus & $\begin{array}{c}\text { (TITLE-ABS-KEY ("family firm" OR "family firms") AND } \\
\text { TITLE-ABS-KEY ("conflict of interest" OR "conflicts of } \\
\text { interest") AND TITLE-ABS-KEY ("corporate governance") }\end{array}$ & 5 \\
\hline
\end{tabular}

Fonte: Os autores do trabalho (2021)

Figura 2 - Refinamento da Base de Dados (usando Mendeley)

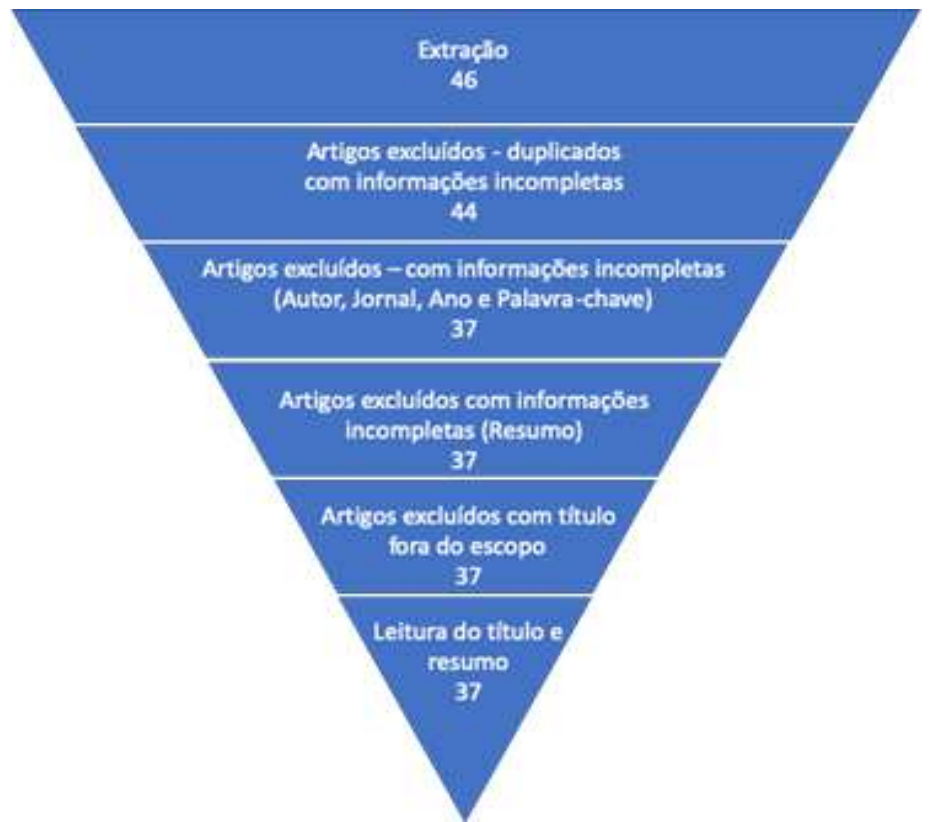


Fonte: Os autores do trabalho (2021).

Tabela 2 - Palavras-chave co-ocorrentes mais frequentes nos títulos e resumos

\begin{tabular}{|c|c|}
\hline Palavra-chave & Ocorrências \\
\hline corporate governance & 29 \\
\hline family firms & 25 \\
\hline ownership structure & 7 \\
\hline agency theory & 5 \\
\hline family ownership & 5 \\
\hline principal conflicts & 4 \\
\hline
\end{tabular}

Fonte: Os autores do trabalho (2021).

Figura 3 - Palavras-chave mais frequentes nos títulos e resumos (gerado usando www.wordclouds.com)

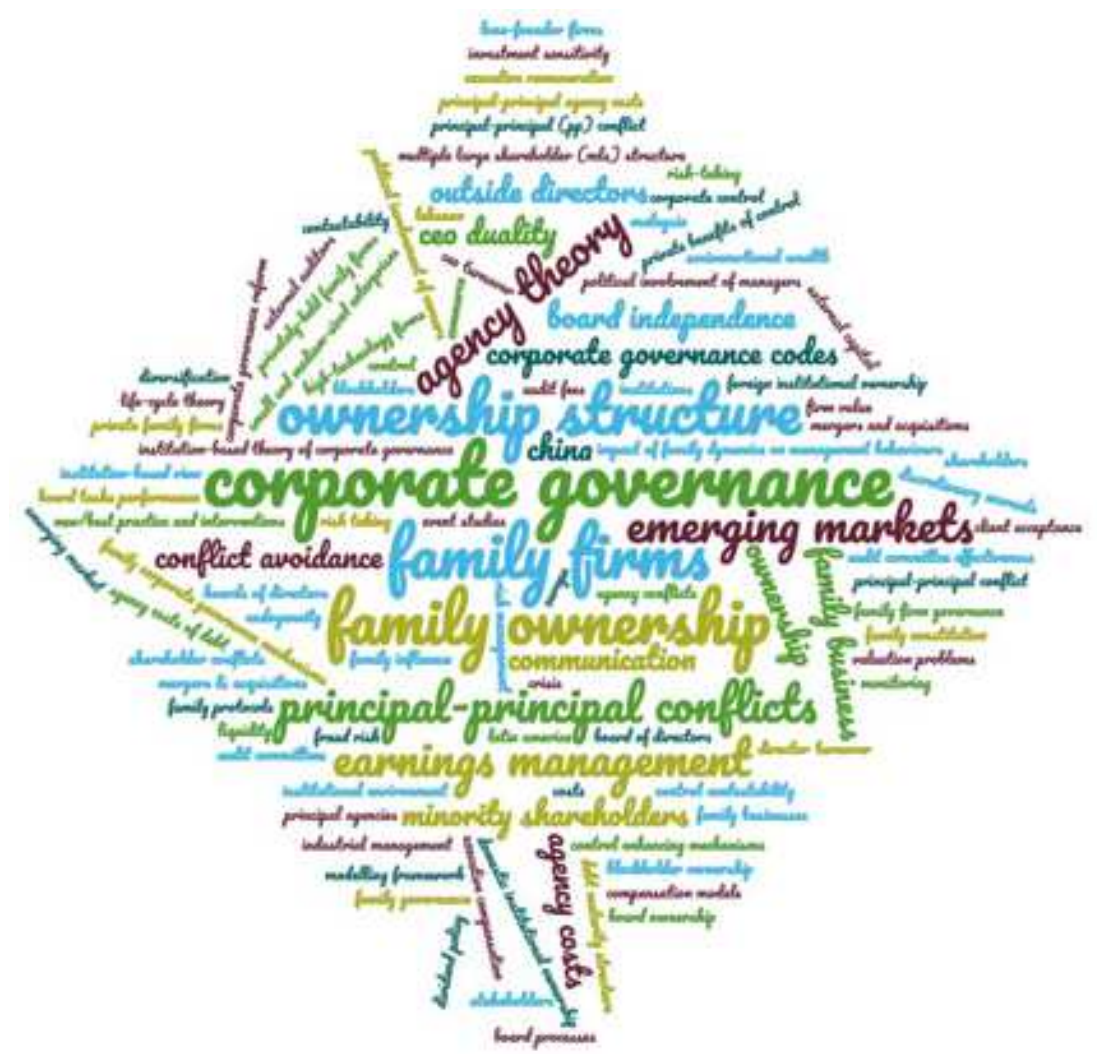

Fonte: Os autores do trabalho (2021). 
Tabela 3 - Autores mais produtivos

\begin{tabular}{|l|c|c|c|}
\hline \multicolumn{1}{|c|}{ Autor } & $\begin{array}{c}\text { Qtde. } \\
\text { Documentos }\end{array}$ & Citações & $\begin{array}{c}\text { Força Total do } \\
\text { Link }\end{array}$ \\
\hline Anderson R.C. & 2 & 1296 & 3 \\
\hline Reeb D.M. & 2 & 1296 & 3 \\
\hline Mansi S.A. & 1 & 695 & 2 \\
\hline Maury B. & 1 & 443 & 0 \\
\hline Dino R.N. & 1 & 338 & 3 \\
\hline Ling Y & 1 & 338 & 3 \\
\hline Lubatkin M.H. & 1 & 338 & 3 \\
\hline Schulze W.S. & 1 & 338 & 2 \\
\hline Jiang Y. & 2 & 175 & 2 \\
\hline Peng M.W. & 2 & 175 & 2 \\
\hline Jara-bertin M. & 1 & 87 & 2 \\
\hline López-de-foronda O. & 1 & 87 & 12 \\
\hline López-iturriaga F.J. & 1 & 87 & 21 \\
\hline Guzmán A. & 4 & 71 & 2 \\
\hline Trujillo M.A. & 4 & & 2 \\
\hline
\end{tabular}

Fonte: Os autores do trabalho (2021).

\section{Figura 4 - Rede de palavras-chave co-ocorrentes}

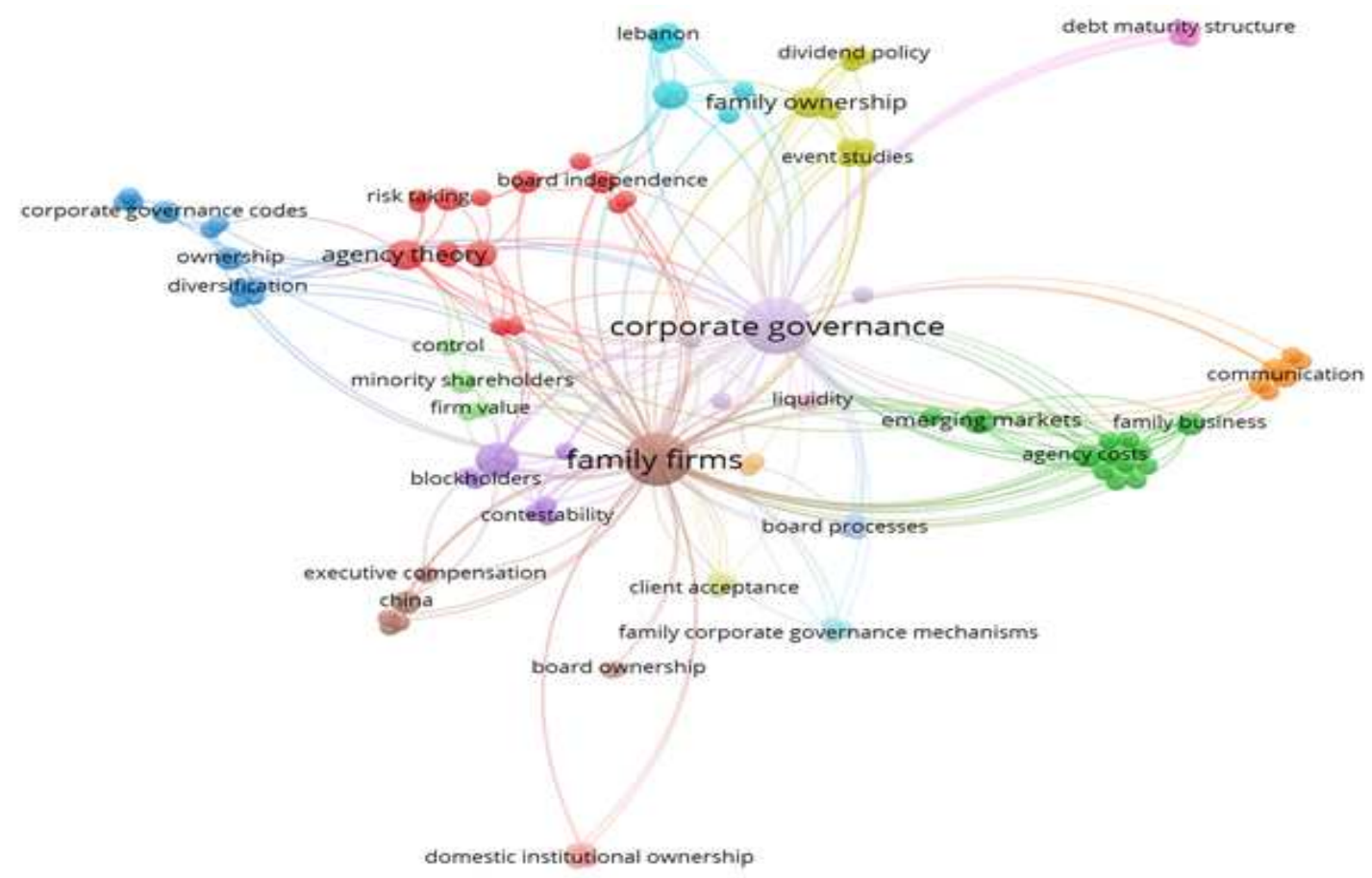

Fonte: Os autores do trabalho (2021). 
Figura 5 - Densidade de palavras-chave co-ocorrentes

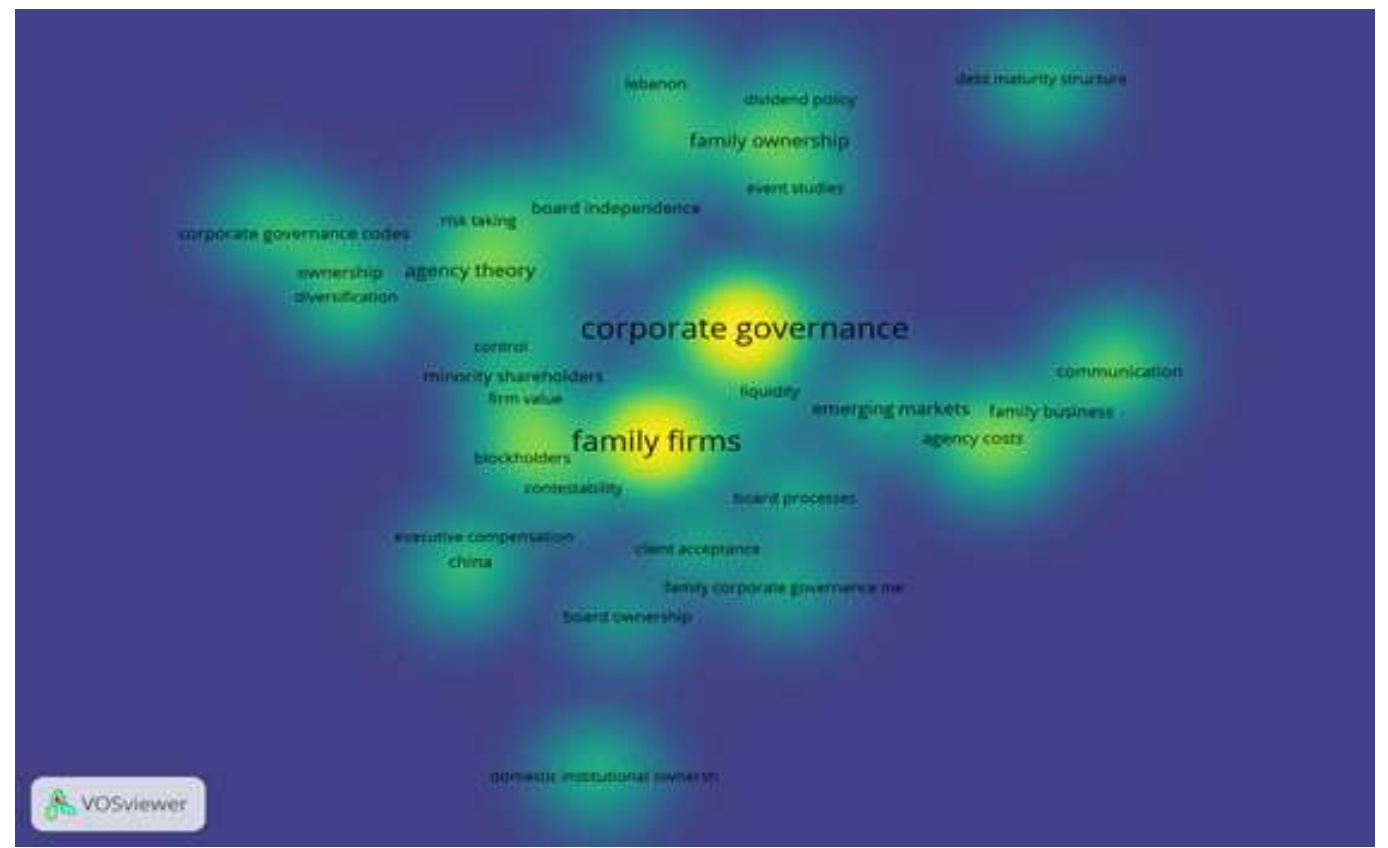

Fonte: Os autores do trabalho (2021).

\section{Figura 6 - Visualização da rede de coautoria}

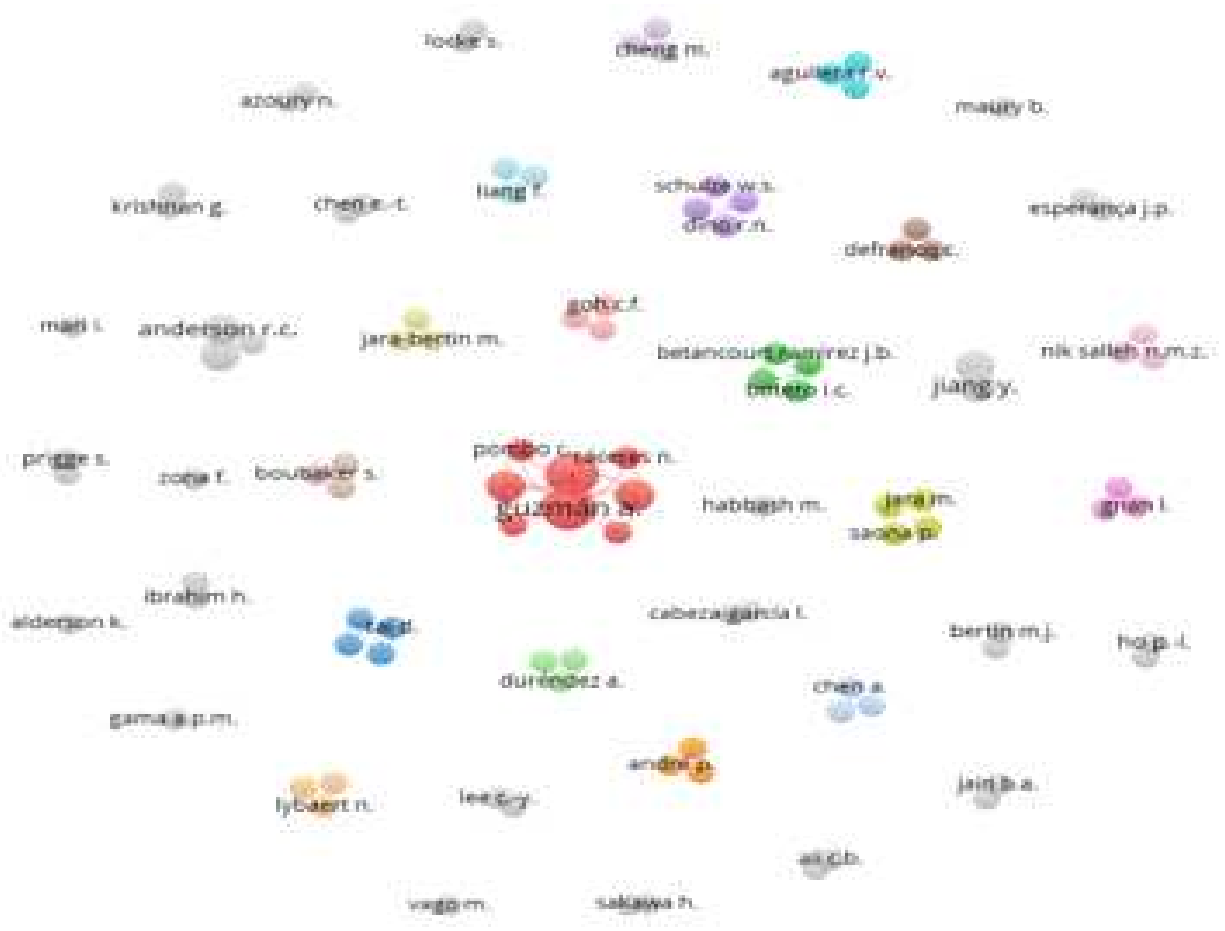

Fonte: Os autores do trabalho (2021). 
Tabela 5 - Os principais periódicos de origem

\begin{tabular}{|l|c|}
\hline \multicolumn{1}{|c|}{ Periódico } & Qtde. Publicações \\
\hline Asia Pacific Journal of Management & 4 \\
\hline Corporate Governance: An International Review & 4 \\
\hline Journal of Family Business Management & 3 \\
\hline Journal of Corporate Finance & 2 \\
\hline Journal of Family Business Strategy & 2 \\
\hline Journal of Management and Governance & 2 \\
\hline Corporate Ownership and Control & 2 \\
\hline Family Business Review & 2 \\
\hline
\end{tabular}

Fonte: Os autores do trabalho (2021).

Tabela 6 - Principais instituições mais ativas x país

\begin{tabular}{|l|c|c|}
\hline \multicolumn{1}{|c|}{ Organização } & $\begin{array}{c}\text { Qtde de } \\
\text { Documentos }\end{array}$ & Citaçes \\
\hline $\begin{array}{l}\text { Culverhouse college of commerce, University of Alabama, Tuscaloosa, } \\
\text { United States }\end{array}$ & 1 & 695 \\
\hline $\begin{array}{l}\text { Kogod school of business, American University, Washington, DC } \\
\text { United States }\end{array}$ & 1 & 695 \\
\hline Pamplin college of business, Virginia tech, Blacksburg, United States & 1 & 695 \\
\hline American University, United States & 1 & 601 \\
\hline Temple University, United States & 1 & 601 \\
\hline $\begin{array}{l}\text { Department of finance and statistics, Swedish School of Economics } \\
\text { and business administration, Helsinki, Finland }\end{array}$ & 1 & 443 \\
\hline $\begin{array}{l}\text { Department of management, school of business, University of } \\
\text { Connecticut, Storrs, United States }\end{array}$ & 1 & 338 \\
\hline $\begin{array}{l}\text { School of management, George Mason university, Fairfax, United } \\
\text { States }\end{array}$ & 1 & 338 \\
\hline $\begin{array}{l}\text { Weatherhead School of Management, case western reserve university. } \\
\text { Cleveland, United States }\end{array}$ & 1 & 338 \\
\hline School of Management, University of Texas at Dallas, United States & 2 & 175 \\
\hline $\begin{array}{l}\text { College of business and economics, California State University, East } \\
\text { Bay, United States }\end{array}$ & 1 & 108 \\
\hline $\begin{array}{l}\text { New Developments in Business Management Program, University of } \\
\text { Valladolid, Spain }\end{array}$ & 1 & 87 \\
\hline University of Burgos, Spain & 1 & 87 \\
\hline $\begin{array}{l}\text { University of Valladolid, department of financial economics and } \\
\text { accounting, Valladolid, Spain }\end{array}$ & 1 & 68 \\
\hline Bi Norwegian Business School, Norway & 1 & 68 \\
\hline Parthenope University, Sda Bocconi School of Management, Italy & 1 & 1 \\
\hline Tor Vergata University, Italy & $\begin{array}{l}\text { Department of management, College of business and economics, } \\
\text { California State University, East Bay, United States }\end{array}$ & 1 \\
\hline
\end{tabular}

Fonte: Os autores do trabalho (2021). 


\section{RESULTADOS E DISCUSSÕES}

Pode-se observar que existe uma quantidade significativa de pesquisas científicas que trata de ações mitigatórias para os principais conflitos em empresas familiares. Inúmeras propostas de mitigação foram citadas entre elas destaque para: implementar conselheiros externos independentes, acordo ou protocolo familiar, articulação explícita das responsabilidades, demandas e recompensas da afiliação familiar, terapeuta e/ou mediador especializado, simetria de informações entre sócios ou cotistas, auditorias externas entre outros.

O conflito de Agência ocorre com menos intensidade em empresas familiares, o que ocasiona uma lacuna de estudo relacionada às práticas de governança corporativa voltadas à administração. Na tabela 3, verifica-se que o termo "teoria de agência" é citado cinco vezes nos títulos ou resumos dos artigos. No entanto, o conflito de Agência aparece quando a família tem inúmeras empresas ou os herdeiros não assumiram o controle na sucessão. Para esses casos, seria necessário implementar medidas mitigatórias similares às S.A. abertas.

Assim, deve-se avaliar possibilidade de implementar algumas práticas de prevenção de conflito de interesses adotadas em empresas de grande porte, que poderiam ser adaptadas para empresas familiares, visto que é dever da empresa prevenir e evitar toda e qualquer situação, real ou potencial, gerada pelo confronto entre interesses públicos e privados, que possa comprometer o interesse da companhia, prejudicar sua reputação ou influenciar, de maneira imprópria, o desempenho da respectiva atividade profissional. Naturalmente a implementação de tais medidas tem custo associado e, portanto, devem-se escolher as ações que melhor atacam a questão diagnosticada em cada caso. No item 6 descreveremos tais medidas.

\subsection{Prevenção e Mitigação de conflito de interesses}

O conflito de interesses é caracterizado quando alguém agir para atingir interesses particulares, contrários à empresa ou que possam causar qualquer tipo de dano à corporação. As formas de mitigar ou prevenir esses conflitos incluem incremento na governança corporativa, escolha de conselheiros externos isentos, firmar acordo ou protocolo da família. No primeiro caso, incrementar processos, costumes, políticas e instituições que afetam a forma de controle - e esse é o desafio da governança. Verifica-se que tanto a propriedade quanto o envolvimento da família estão negativamente relacionados à tomada de risco nas decisões. 
Os efeitos dos conselheiros externos nas análises de risco têm um resultado positivo e significativo nas decisões e tomadas de risco. Moderam positivamente a relação entre família e tomada de riscos. Weichieh Su et al (2012) mostraram que as empresas familiares têm maior aversão a risco em relação aos conselheiros externos. Por fim, com relação ao protocolo familiar, Van der Heyden et al. (2005) descreve a importância da justiça nas relações interfamiliares relacionadas com a empresa familiar. O protocolo familiar é uma importante ferramenta de mitigação de conflito, pois quando as famílias não têm uma articulação explícita das responsabilidades, demandas e recompensas da afiliação familiar em relação aos negócios, elas criam "contratos psicológicos" entre empresa e família. Essas irrealistas expectativas podem afetar os sentimentos de justiça, os níveis de conflito de familiares nas relações com a empresa podem diminuir o comprometimento da família e envolvidos.

Para resolver o problema de governar a administração sob vários acionistas, estudiosos descobriram que se cria assimetria de informação na nomeação de acionista sem um protocolo familiar e conselho da família. Esses dois elementos são ferramentas capazes de mitigar a assimetria de informações e as expectativas desalinhadas à realidade. São diversas expectativas e diferentes funções que podem desempenhar cada familiar e os requisitos para essas funções, ou os benefícios e responsabilidades que vêm com a propriedade (WEICHIEH SU et al, 2012).

\subsubsection{Implantação de um Código de Ética}

Com objetivo de minimizar a probabilidade de ocorrência de conflito de interesses e nepotismo, é sugerido que a empresa estabeleça de forma clara os deveres de todos os seus empregados, tais como exemplificados nas figuras 7 e 8 abaixo: 


\section{Figura 7 - Condicionantes para um Código de ética}
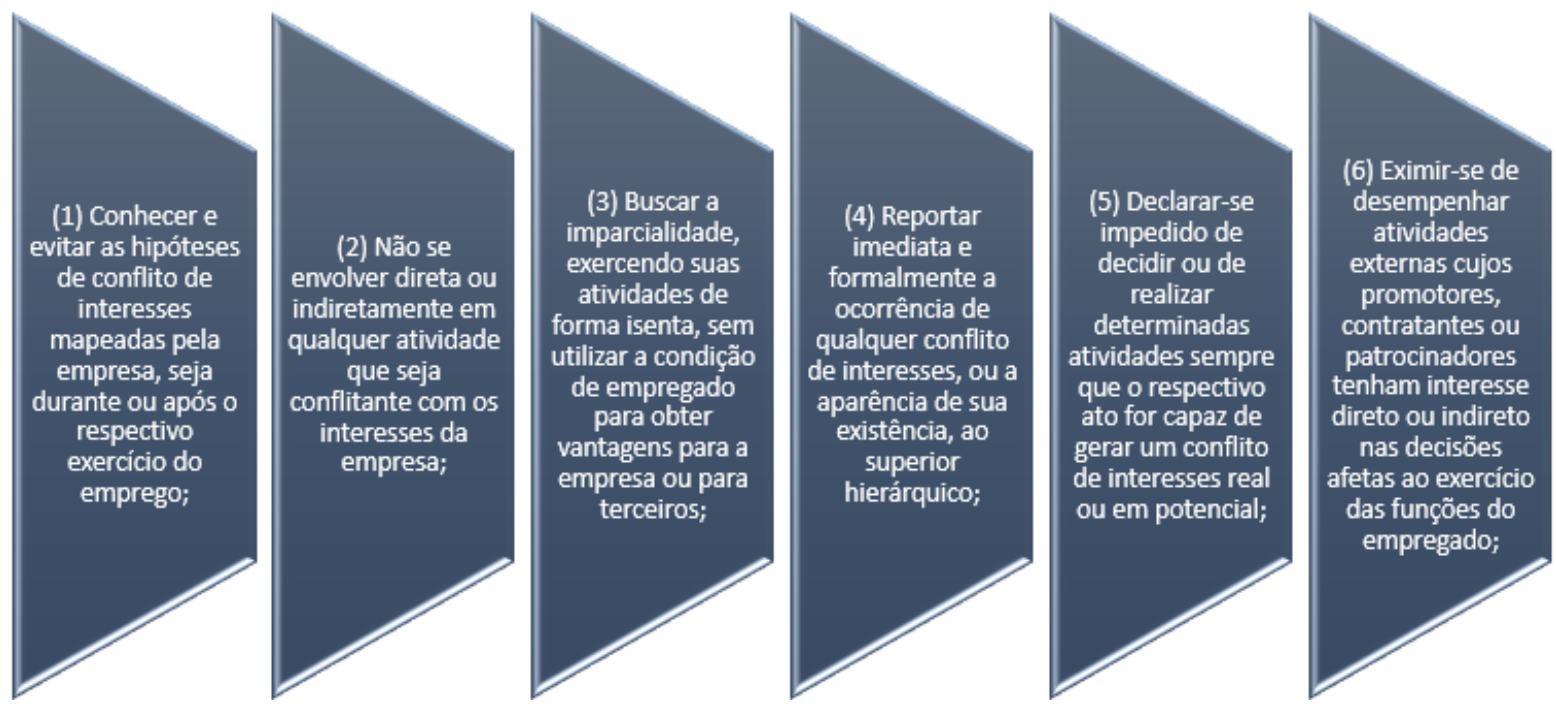

Fonte: Os autores do trabalho (2021).

Figura 8 - Condicionantes para um Código de ética
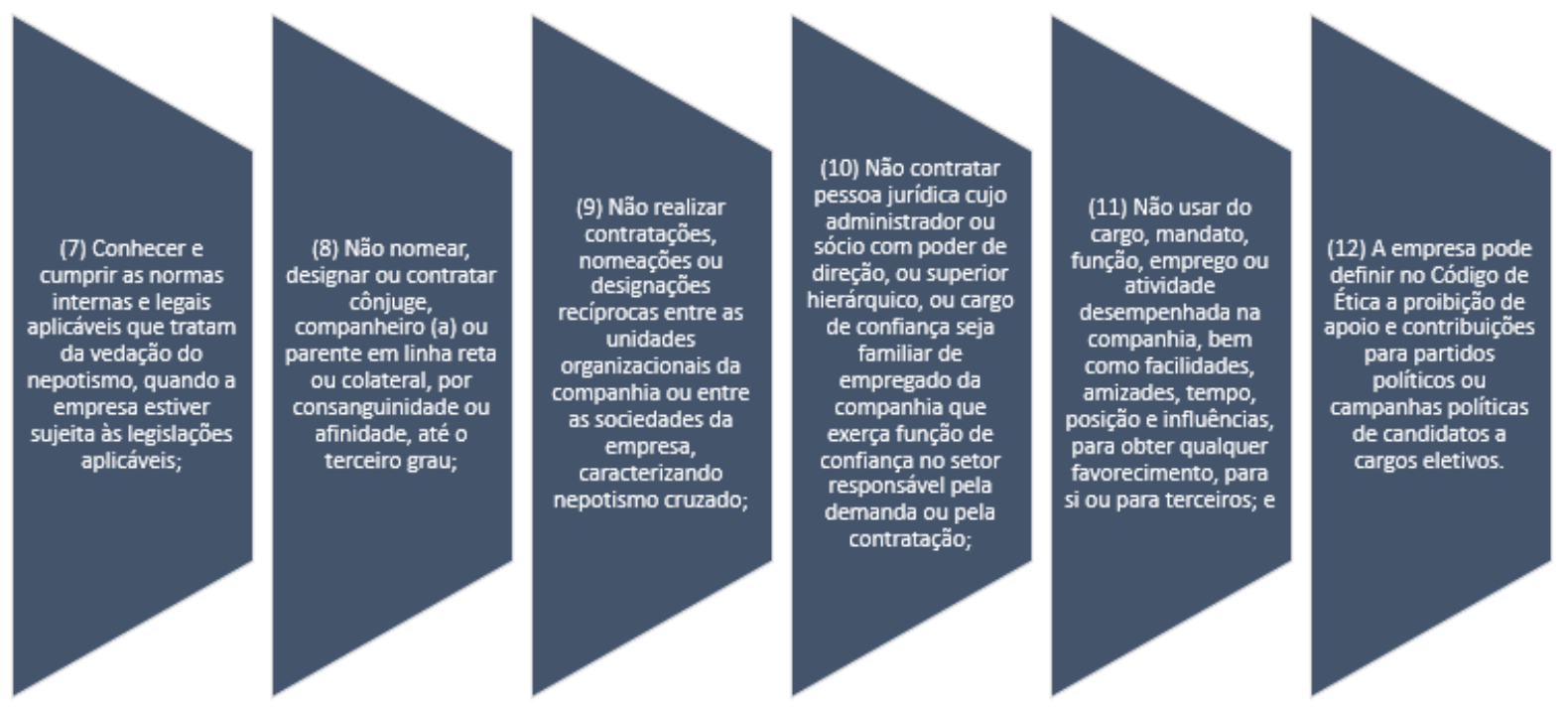

Fonte: Os autores do trabalho (2021).

É sugerido que o Código de Ética estabeleça a necessidade de que tanto os administradores quanto os funcionários da empresa pautem sua conduta de acordo com os mais altos padrões éticos, evitando qualquer conflito de interesse. 


\subsubsection{Política de Transação com Partes Relacionadas}

A Política de Transações com Partes Relacionadas poderia estabelecer que os princípios presentes na celebração desse tipo de transação e em situações em que haja potencial conflito de interesses. Assim, assegurar a comutatividade das operações e a preservação de interesses da empresa, em alinhamento com a transparência nos processos e as melhores práticas de governança corporativa e às exigências legais. Essa política também buscaria assegurar o adequado e diligente processo decisório da administração da empresa, observando as condições de mercado e mecanismos de remuneração adequados. Devem-se utilizar as hipóteses e provisões: (1) Priorização dos interesses da empresa, independentemente da contraparte; (2) condições de mercado; (3) Cumprimento das condições de mercado, especialmente quanto a prazos, preços e garantias ou com pagamento compensatório adequado; (4) Divulgação precisa e oportuna de acordo com as autoridades aplicáveis.

As Transações com Partes Relacionadas devem ser conduzidas em observância às condições de mercado, especialmente no que diz respeito a prazos, preços e garantias, conforme aplicável, observando o pagamento compensatório adequado.

\subsubsection{Estatuto Social - Estabelecimento de Regras}

Definir no Estatuto Social da empresa como pré-requisito que, para ocupar cargo de administração, o candidato não tenha quaisquer conflitos de interesse com a empresa e observe, integralmente, os requisitos e vedações legais quando a empresa estiver sujeita a tais legislações. Tal premissa deveria ser reforçada por Diretrizes de Governança Corporativa, pelo Código de Ética e por Regimento Interno. Caso algum dos membros do Conselho mude de ocupação principal após a sua eleição, recomenda-se que o fato seja levado a um colegiado, que reavaliará os requisitos, impedimentos e conflitos. No caso de conselheiro representante dos empregados, por exemplo, esse não deve participar de discussões e deliberações em pauta sobre a fixação da política de RH que envolvam assuntos de relações sindicais, remuneração, benefícios e vantagens, inclusive matérias de previdência complementar e assistenciais. 
4.1.4 Canal de Comunicação para consultas sobre conflito de interesses

É sugerido que a empresa mantenha instrumentos de comunicação disponíveis aos empregados para a realização de consultas sobre potenciais situações de conflito de interesses e solicitação de autorização para exercer atividades que, em função de sua natureza, possam ser conflitantes com os interesses da empresa.

4.1.5 Regras de término de gestão dos administradores e membros do conselho fiscal

É sugerido que a empresa estabeleça no seu Estatuto Social ou de outras formas, a previsão de hipóteses de conflito de interesses posterior ao término de gestão dos administradores e membros do conselho fiscal, impedindo-os de exercer determinadas atividades, por um período de alguns meses, mediante remuneração compensatória, cujo início do pagamento está condicionado à caracterização do conflito de interesse e o impedimento para o exercício de atividade profissional e será precedido de manifestação formal sobre a caracterização de conflito.

4.1.6 Mitigação de conflito de interesse entre acionistas e membros da alta administração

É sugerido que as Diretrizes de Governança Corporativa estabeleçam que o Conselho de Administração tem como princípio monitorar e gerenciar potenciais conflitos de interesses entre acionistas e membros da alta administração da Companhia. Adicionalmente é sugerido que haja um regimento interno do Conselho de Administração estabelecendo que este Colegiado deverá adotar a prática da sessão executiva para tratar das matérias em que possa existir conflito de interesses.

\subsubsection{Implantação de políticas e diretrizes sobre conflito de interesses}

Exemplos de políticas e diretrizes relacionadas a conflito de interesses são: (i) Estabelecimento de um Código de Ética que considere conflito de interesses como sendo qualquer situação gerada pelo confronto entre os interesses da empresa e os interesses particulares dos empregados da companhia e daqueles abrangidos pelo código de ética, que possa vir a comprometer os interesses da empresa ou influenciar de maneira imprópria o desempenho das atividades dos empregados da empresa; (ii) determinação de que os 
colaboradores da empresa, entre eles os membros dos Conselhos de Administração, dos Conselhos Fiscais, das Diretorias Executivas, os ocupantes de funções gerenciais, os empregados, os estagiários e os prestadores de serviços, não devem se envolver em qualquer atividade que seja conflitante com os interesses da empresa e devem comunicar aos superiores hierárquicos ou às Ouvidorias qualquer situação que configure aparente ou potencial conflito de interesses e (iii) criação de uma política corporativa independente, específica de conflito de interesses, parte de um programa de integridade, desdobrada para todas as áreas e processos. Alinhamento interno da empresa em relação ao significado e tratamento do conflito de interesse com outros riscos de Compliance, como nepotismo, brindes e presentes, etc., que são tipos de conflito de interesses, mas tratados de formas diversas. Criação de um dicionário de situações de conflito de interesses a ser divulgado para toda empresa.

\subsubsection{Comunicação e treinamento}

É sugerido que haja uma política de comunicação ampla para disseminação e treinamento de como os funcionários devem identificar e tratar os conflitos de interesses (a quem comunicar quando identificar um risco percebido/potencial/real, como comunicar e quando comunicar), para o tratamento adequado dos riscos de conflito de interesses.

\subsubsection{Implantação de Regime Disciplinar e Comitê de Aplicação de Sanção}

Referente à falta de dispositivo que garanta a sanção para os assuntos relacionados a conflito de interesses, a empresa poderia implantar um Comitê para reforçar o sistema de consequências, orientando, uniformizando e acompanhando a aplicação de sanções em casos relacionados a conflito de interesses.

\section{CONSIDARAÇÕES FINAIS}

Fica evidente que mesmo nas empresas de origem familiar e menores podem-se constatar fortes conflitos de interesse que com frequência destroem valor da empresa e a impedem de tomar riscos adequados às melhores oportunidades de investimento e retorno à empresa. Em empresas familiares o conflito mais citado e que demonstra destruir mais valor é o principal-principal. 
O item 5 oferece uma série de ferramentas para mitigar conflitos. Destacamos, no entanto, a simples adoção de conselho de administração com conselheiros externos competentes e isentos, preferencialmente especializados na área de negócio da empresa e em finanças. Pelo menos dois para um conselho de cinco membros ou mais de dois para conselhos com sete ou nove membros. Entre as atribuições constantes nos contratos desses profissionais, deve-se destacar mediação, controle e questões para fazer desses a principal estratégia contra conflitos principal-principal, principal-agência, conflito cognitivo e intrafamiliar visando otimizar os resultados da companhia.

Sugerimos nova pesquisa considerando os termos "governance", "corporate governance", “codes," “principles," "guidelines", "family businesses" e "family companies".

\section{REFERÊNCIAS}

ALI, C. B. Audit Fees in Family Firms: Evidence from U.S. Listed Companies. The Journal of Aplplied Business Research, v. 30, n. 3. Littleton, CO. Estados Unidos, 2014.

ALVES, C. A. M. As contribuições das ouvidorias para a gestão e para a governança corporativa: estudo em instituições bancárias baseado na regulamentação brasileira. Tese (Doutorado) - Universidade de São Paulo, São Paulo, 2012.

AMBROZINI, M. A. Políticas de dividendos no Brasil: um modelo de apoio à decisão. Tese (Doutorado) - Universidade de São Paulo (FEA-RP/USP), Ribeirão Preto, SP, 2011.

ANDRÉ, P.; BEN-AMAR, W; SAADI, S. Family firms and high technology Mergers \& Acquisitions. J Manag Govn. 18. J Manag Gov, p. 129-158, 2014.

AZOURY, N.; BOURI, E. Principal conflicts in Lebanese unlisted family firms. J Manag Gov. Nova Iorque, 2014.

BARRETTO, C. R. Fatores Críticos de Insucesso na Implantação de Projetos: um survey entre profissionais em uma empresa integrada de energia no Brasil. Dissertação (Mestrado) Universidade Federal Fluminense, Niterói, 2011.

BERTIN, M. J.; ITURRIAGA, F. J. L. Earnings management and the contest to the control: an international analysis of family-owned firms., Spanish Journal of Finance and Accounting. Revista Española de Financiación y Contabilidad, 43:4, 355-379, 2014.

CANTON, V. I. M.; SIRTUlli, R.; SILVA, G. Análise da Influência do Conselho de Administração na Evidência da Sustentabilidade. Revista Metropolitana de Sustentabilidade/ FMU. ISSN: 2318.3233. São Paulo, 2019.

CHAU, G.; GRAY, S. J. Family ownership, board independence and voluntary disclosure: Evidence from Hong Kong., Journal of International Accounting, Auditing and Taxation, v. 19, Issue 2, p. 93-109, ISSN 1061-9518, 2010. 
CHENG, M. et al. Executive compensation in family firms: The effect of multiple family members, J. Corp. Finance, 2014. DOI: http://dx.doi.org/10.1016/j.jcorpfin.2014.10.014.

COIMBRA, F. C. Estrutura de governança corporativa e gestão de riscos: um estudo de casos no setor financeiro. Tese (Doutorado) - Universidade de São Paulo, São Paulo, 2011.

CONZATTI, E. R.; BESEN, F. G.; JUNIOR, V.S. Índice de Governança Corporativa em empresas listadas na B3. Revista ConTexto, v. 20, n. 45, Porto Alegre, 2020.

CORBETTA, G. SAlVATO, C. A. The Board of Directors in Family Firms: One Size Fits All? Family Business Review, v. XVII, n. 2, Sage Publishing, 2004.

COSTA, M. R. S. M. Avaliação do desempenho de empresas de energia elétrica no Brasil sob a ótica de variáveis ambientais, sociais e de governança corporativa. Dissertação (Mestrado) - USP, São Paulo, 2018.

CUNHA, V.; RODRIGIES, L. L. Determinants of Structure of Corporate Governance Disclosure in Portugal. Rev. Bras. Gest. Neg, São Paulo, v. 20, n. 3, jul-set. 2018, p. 338360 .

DE OLIVEIRA, M. C; LINHARES, J. S. A Implantação de Controle Interno adequado às Exigências da Lei Sarbanes-Oxley em Empresas Brasileiras: Um Estudo de caso. Base Revista de Administração e Contabilidade da Unisinos, 4(2):160-170, mai./ago. 2007.

FARIA, A. L. Financiamento público de apoio a inovação: um estudo de empresas incubadas de base tecnológica no Estado de São Paulo. Dissertação (Mestrado) - USP, São Paulo, 2015.

FERREIRA, F. Desafio aceito: o impacto do acionista minoritário forte. Dissertação (Mestrado) - USP, São Paulo, 2019.

FREZATTI, F. et al. Estágios do ciclo de vida e perfil de empresas familiares brasileiras. RAE-Revista de Administração de Empresas, FGV EAESP, São Paulo, 2017.

GOH, C.; RASLI, A; KHAN, S. CEO duality, board independence, corporate governance and firm performance in family firms: Evidence from the manufacturing industry in Malaysia. Macmillan Publishers Ltd, 1472-4782. 2014.

GONZÁLEZ, M. et al. The Role of Family Involvement on CEO Turnover: Evidence from Colombian Family Firms. Corporate Governance: An International Review / vol23. 2014.

GUIMARÃES, T. M., A compensação dos gestores, a sustentabilidade empresarial e os impactos no desempenho, valor e risco das empresas brasileiras. Dissertação (Mestrado) UFU, Uberlândia, 2014.

HABBERSHON, T. G.; JOSEPH, H. A. Research Note: Perceptions are Reality: How Family Meetings Lead to Collective Action. Family Business Review, 10.1 (1997): 37-52. Print. 
ISABEL, C. et al. Family protocols as governance tools. Journal of Family Business Management, v. 5, Iss 2, pp. 218-237, 2015.

ISHAK, I. et al. Family Control and Earnings Management: Malaysia Evidence. 2nd International Conference on Economics, Business and Management IPEDR, v.22, IACSIT Press, Singapore, 2011.

J., Luo et al. Multiple large shareholder structure and governance: the Role of shareholder numbers, contest for control, and formal institutions in chinese family firms. Management and Organization Review Review, 9:2, p. 265-294,2013.

KARAM, P. B. S. Conflitos em conselhos de empresas familiares: investigação sobre antecedentes e consequências no processo decisório estratégico. Doutorado - USP, 2019.

KEANON, A. Conflict management and resolution in family-owned businesses. Journal of Family Business Management, v. 5, Iss 2, pp. 140-156, 2015.

MACIEL, M. L; ALBAGLI, S. Cooperação Internacional na Era do Conhecimento. Brasília: Centro de Gestão e Estudos Estratégicos, p. 10-23; Il.; 24 cm ISBN 978-85-60755-18-9, 2010.

MARTINS, A. et al. Empresa familiar e as dificuldades enfrentadas pelos membros da terceira geração. Revista de Ciências da Administração, v. 10, n. 22, UFSC, 2008.

PAN, M. F. et al. Empresas Familiares, a Sucessão e a Prevenção de Conflitos entre Sócios: Um Estudo em uma Empresa Comercial do Segmento de Suprimentos Industriais. Anais Centro de Ciências Sociais Aplicadas, ISSN 2526-8570, [S.1.], v. 6, n. 1, p. 82-98, 2019.

PETTY, R. S. Governança Corporativa, sustentabilidade e a perenidade de empresas brasileiras de capital fechado: caso Agroterenas. 2015.

PHILIPPI, Jr., A.; F. V. Práticas da Interdisciplinaridade no Ensino e Pesquisa. 1 ed. São Paulo: Manole, São Paulo, 2016.

RIBEIRO, H. C. M. Produção Acadêmica dos temas Governança Corporativa e Sustentabilidade: uma análise dos últimos 14 anos nos periódicos internacionais. Revista Economia e Gestão, Puc Minas, Belo Horizonte, 2014.

SANTOS, S. R. Y. Desenvolvimento de Empresas Baseadas em Ativos de Conhecimento: uma investigação empírica das atividades de formação e evolução da base de recursos. Tese (Doutorado) - COPPE/UFRJ, Rio de Janeiro, 2017.

STOCKMANS, A.; LYBAERT, N.; VOORDECKERS, W. The conditional nature of board characteristics in constraining earnings management in private family firms. Journal of Family Business Strategy, v. 4, Issue 2, 2013.

SU, W; LEE, C.Y. Effects of corporate governance on risk taking in Taiwanese family firms during institutional reform. Asia Pac J Manag (2013), DOI 10.1007/s10490-012-9292-x. 
TOLEDO, R. et al. A cientometric review of global research on sustainability and project management dataset. Data in brief 25 (2019) 104312.

TROCCOLI, I. R., LISBOA, F, Governança corporativa na empresa familiar: uma conciliação possível? Revista Vianna Sapiens, 9(1), 32. DOI: https://doi.org/10.31994/rvs.v9i1.291, 2018.

VILlAlOnGA, B. et al. Governance of Family Firms. Annu Rev, Finance Economics, DOI: 10.1146/annurev-financial-110613-034357, 2015.

ZONA, F. Board ownership and processes in family firms. Small Business Economics. Springer Science + Business Media New York, 2014.

\section{Como Referenciar este Artigo, conforme ABNT:}

FERREIRA, M. P; GOMES, J. S; FREIRE, F. B. Uma Revisão Cienciométrica da Governança e dos Conflitos em Empresas Familiares. Rev. FSA, Teresina, v.19, n. 2, art. 2, p. 23-48, fev. 2022.

\begin{tabular}{|l|c|c|c|}
\hline \multicolumn{1}{|c|}{ Contribuição dos Autores } & $\begin{array}{c}\text {. P. } \\
\text { Ferreira }\end{array}$ & $\begin{array}{c}\text { J. S. } \\
\text { Gomes }\end{array}$ & $\begin{array}{c}\text { F. B. } \\
\text { Freire }\end{array}$ \\
\hline 1) concepção e planejamento. & $\mathrm{X}$ & $\mathrm{X}$ & $\mathrm{X}$ \\
\hline 2) análise e interpretação dos dados. & $\mathrm{X}$ & & $\mathrm{X}$ \\
\hline 3) elaboração do rascunho ou na revisão crítica do conteúdo. & $\mathrm{X}$ & $\mathrm{X}$ & \\
\hline 4) participação na aprovação da versão final do manuscrito. & $\mathrm{X}$ & $\mathrm{X}$ & $\mathrm{X}$ \\
\hline
\end{tabular}

